\title{
Right atrial myxoma: an echocardiographic study
}

\author{
J. PERNOD, A. PIWNICA, AND J. C. DURET \\ From the Army Cardiological Department, Hopital Percy, 92141 Clamart (France) and the Cardiovascular \\ Surgery Department, Hôpital Broussais, 96, rue Didot-75014 Paris, France
}

SUMMARY A case of right atrial myxoma is reported in a 29 -year-old man. Though it was a large tumour, the diagnosis remained unsuspected for a long time.

Multiple echo recordings strongly contributed to the diagnosis. After surgical removal, the postoperative course was uneventful.

Since Banhson and Newman first described surgical removal of a right atrial myxoma, the importance of the recognition of these tumours has been widely emphasised.

This report presents a case where echocardiography proved very useful in establishing the diagnosis.

\section{Case report}

A 29-year-old man was referred to the cardiological department in October 1976, for worsening dyspnoea and arthralgia.

The past history disclosed that for 18 months he had been complaining of cough, palpitation, and fever $\left(37 \cdot 5-38^{\circ} \mathrm{C}\right)$; on chest $x$-ray examination, the heart was enlarged and the electrocardiogram showed ST-T changes; he was thus thought to have pericarditis and underwent biopsy of the pericardium which showed only non-specific fibrosis.

On admission, his blood pressure was $130 / 80 \mathrm{~mm}$ Hg. Neck veins were not distended. A grade 2/6 protosystolic murmur and a grade $2 / 6$ diastolic murmur were heard at the left sternal border; both were increased by inspiration.

The electrocardiogram showed sinus rhythm, incomplete right bundle-branch block, and diffuse ST-T changes. The chest film showed cardiomegaly with right ventricular enlargement.

The laboratory findings were a high erythrocyte sedimentation rate ( $35 \mathrm{~mm}$ in $1 \mathrm{hr}$, Wintrobe) and a white blood cell count of 13200 with 80 per cent neutrophils. The other blood chemistry values were within the normal range.

Echocardiography was then performed (Echeovideorex-CGR-2.25 $\mathrm{MHz}$.)

Fig. 1 shows intracardiac echoes, anterior to a normal aorta, and originating from the right ventricular outflow tract, which are recorded by a beam passing through the aortic root. These echoes were identified only during the second part of diastole.

An $M$ mode-scan (Fig. 2) shows the right ventricular diastolic echoes which are identified in the mitral as well as in the aortic recordings. Left heart echograms are normal.

Right heart catheterisation was also performed. The shape of the right atrial pressure curve suggested tricuspid regurgitation (giant $\mathrm{v}$ wave); the mean pressure was $9 \mathrm{mmHg}$ and increased to $17 \mathrm{mmHg}$ during compression of the liver. The right ventricular pressure was $25 / 0-5 \mathrm{mmHg}$.

Cineangiographic studies with injection into the inferior vena cava showed a filling defect within the right atrium (Fig. 3a and $b$ ). The mass was seen to prolapse into the right ventricle during ventricular diastole and return into the right atrium near the inferior vena cava during ventricular systole.

With a presumptive diagnosis of right atrial myxoma, the patient was submitted to open-heart surgery. Operative findings consisted of a large myxoma attached to the interatrial septum between the inferior vena cava and the coronary sinus orifices by a stalk $2 \mathrm{~mm}$ in length. The tumour was removed and an associated dilatation of the tricuspid orifice was corrected by a conservative procedure (Carpentier's ring). Histological examination showed a typical large myxoma $(10 \times 9 \times 4 \mathrm{~cm})$ weighing $165 \mathrm{~g}$.

The postoperative course was uneventful and the patient was discharged on the 15 th postoperative day. On follow-up, the result was considered satisfactory and echocardiography was normal. 


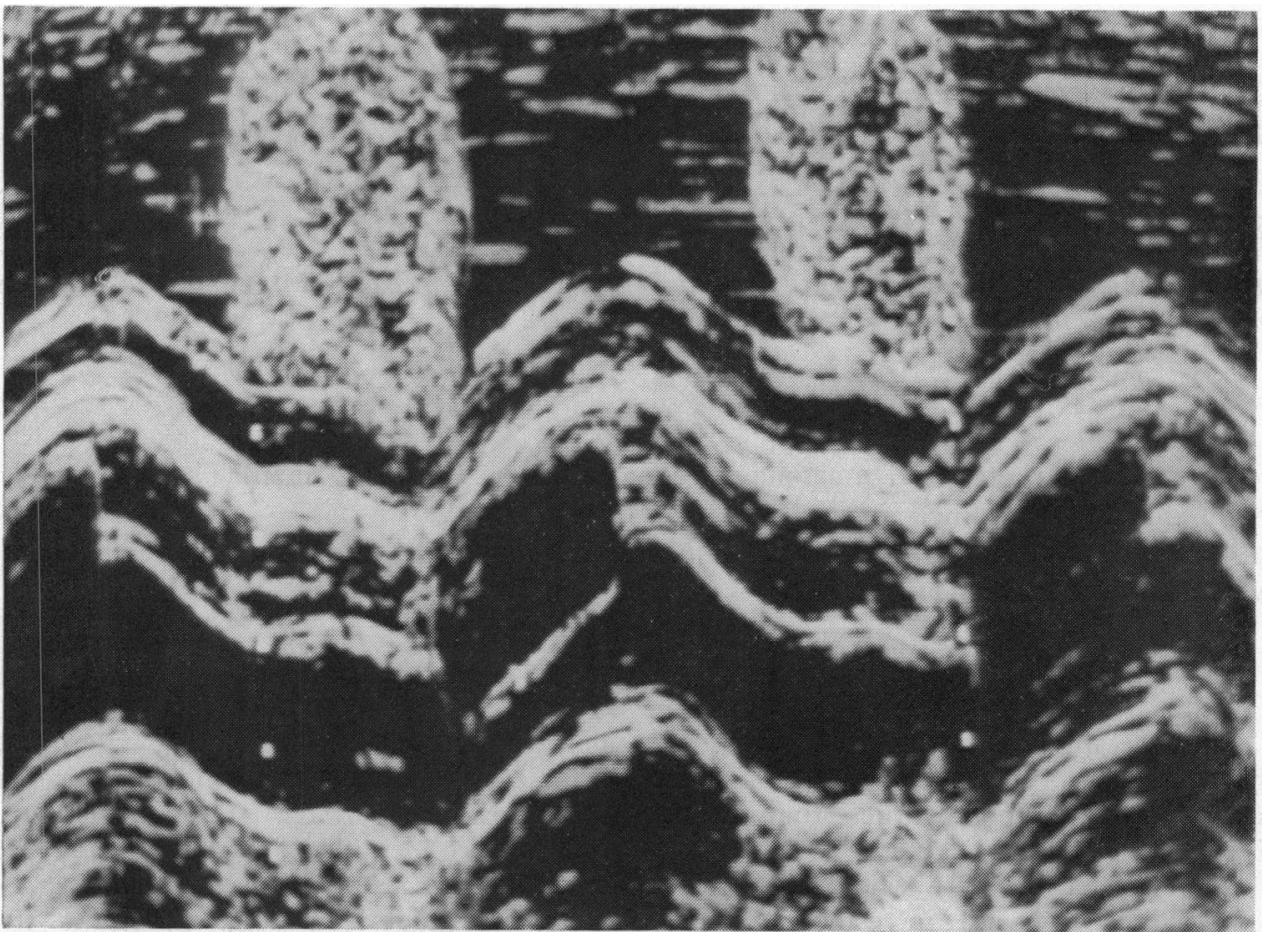

Fig. 1 Echocardiogram-The beam passes through the aortic root. The tumour is represented by a mass of echoes filling the right ventricle during diastole.

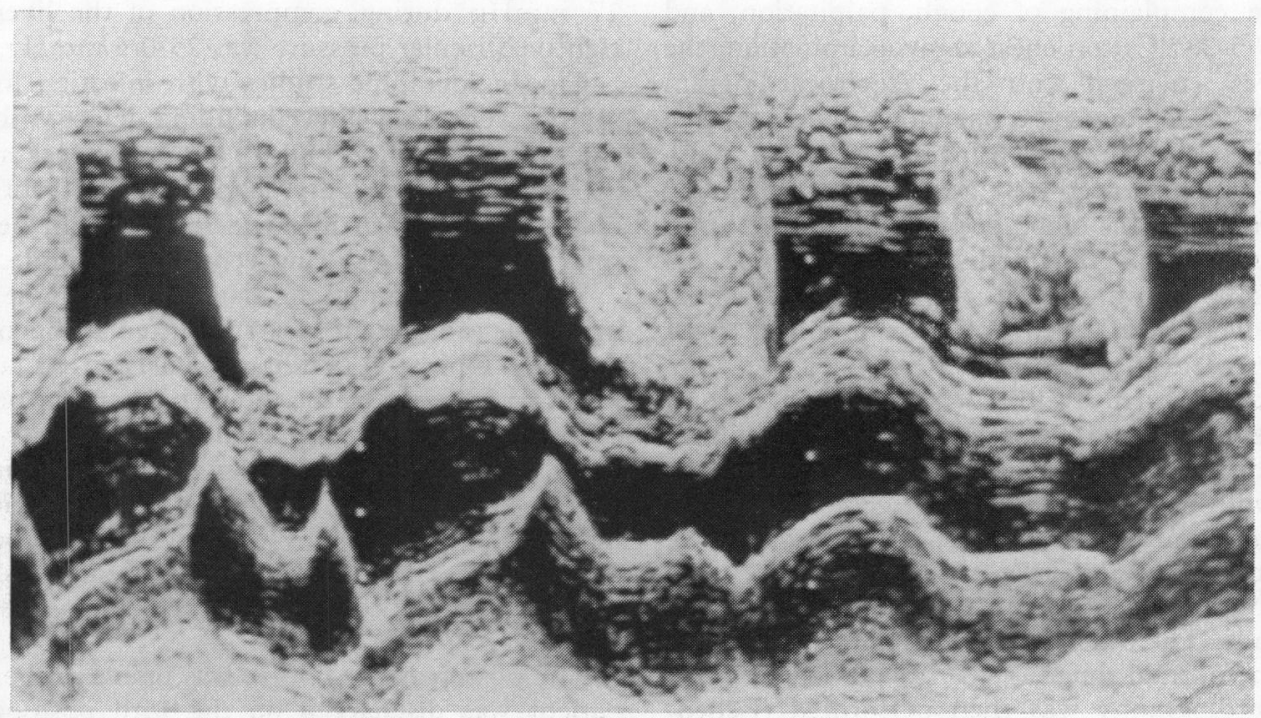

Fig. 2 Echocardiogram-M-mode-scan showing a mass of diastolic echoes within the right ventricle in mitral as well as in aortic records. 


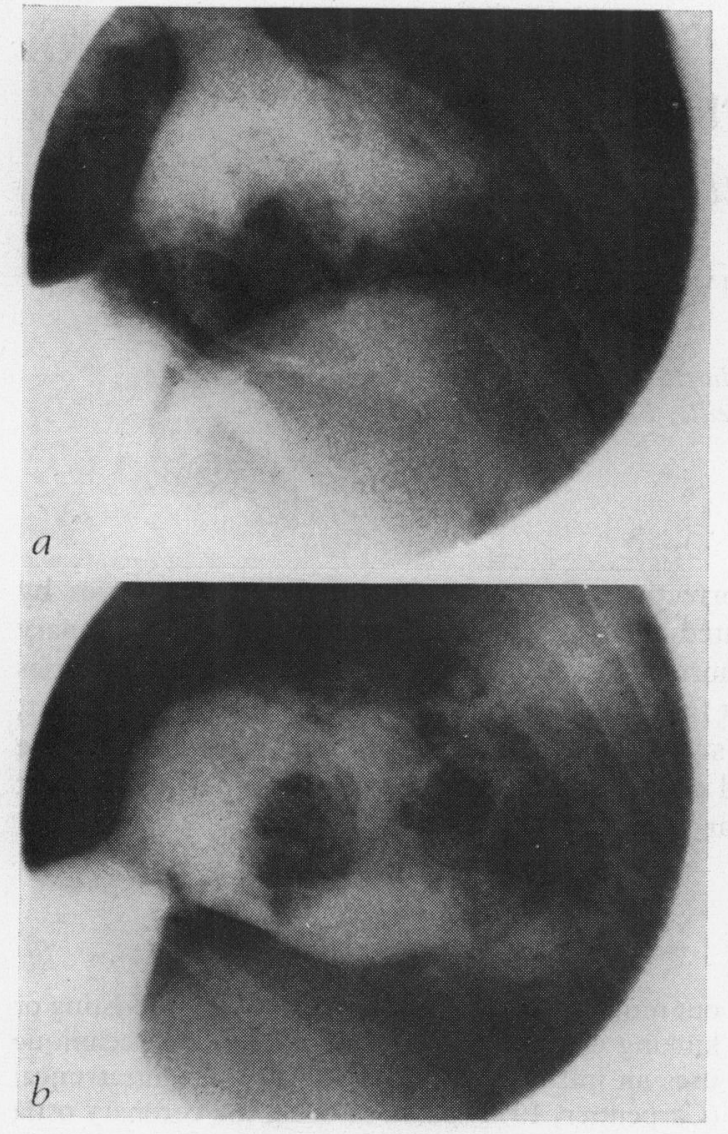

Fig. 3 Selected frames from angiogram showing a large tumour in systole (a) and diastole (b).

\section{Discussion}

Right atrial myxomas are usually difficult to recognise because of their rarity, being three times less common than left atrial myxomas, and because their clinical features are various and may suggest rheumatic disease, mitral stenosis, Ebstein's anomaly, infective endocarditis, or pericarditis, as in our case and that of Yuste et al. (1976).

The differing pictures with which these tumours present emphasise the importance of echocardiography as a noninvasive diagnostic technique.

In reviewing the published reports, we have found 10 cases of right atrial myxoma with an echocardiographic assessment. Since the early reports of Wolfe et al. (1969) and Nasser et al. (1972) (case 8) the ultrasound patterns have been well outlined: a mass of diastolic echoes is located in the right ventricle, posteriorly to the anterior tricuspid leaflet. Identical findings were reported by Goldschlager et al. (1972), Feigenbaum and Chang (1972), Harbold and Gau (1973), Siltanen et al. (1976) (case No. 3), Yuste et al. (1976), and Atsuchi et al. (1976).

In the case reported by Waxler et al. (1972) the abnormal echoes were recorded during diastole and systole; this finding was related to the proximity of the tumour to the valve.

Right atrial myxomas may be associated with other intracardiac lesions: left atrial myxoma (Zajtchuk et al., 1975; Fitterer et al., 1976), and prolapse of the mitral valve (Meyers et al., 1977). These facts emphasise the importance of using ultrasound to explore all chambers of the heart.

\section{References}

Atsuchi, Y., Nagai, Y., Nakamura, K., Komatsu, Y., Osamura, Y., Shibuya, M., and Hirosawa, K. (1976). Echocardiographic diagnosis of prolapsing right atrial myxoma. Fapanese Heart Fournal, 17, 798-803.

Feigenbaum, H., and Chang, S. (1972). Echocardiography, pp. 160-161. Lea and Febiger, Philadelphia.

Fitterer, J. D., Spicer, M. J., and Nelson, W. P. (1976). Echocardiographic demonstration of bilateral atrial myxomas. Chest, 70, 282-284.

Goldschlager, A., Popper, R., Goldschlager, N., Gerbode, F., and Prozan, G. (1972). Right atrial myxoma with right to left shunt and polycythemia presenting as congenital heart disease. American fournal of Cardiology, 30, 82-86.

Harbold, N. B., and Gau, G. T. (1973). Echocardiographic diagnosis of right atrial myxoma. Mayo Clinic Proceedings, 48, 284-286.

Meyers, S. N., Shapiro, J. E., Barresi, V., DeBoer, A. A., Pavel, D. I., Gracey, D. R., Suhre, D. E., and Buehler, J. H. (1977). Right atrial myxoma with right to left shunting and mitral valve prolapse. American fournal of Medicine, 62, 308-314.

Nasser, W. K., Davis, R. H., Dillon, J. C., Tavel, M. E., Helmen, C. H., Feigenbaum, H., and Fisch, C. (1972). Atrial myxoma. II. Phonocardiographic, echocardiographic, hemodynamic, and angiographic features in nine cases. American Heart fournal, 83, 810-824.

Siltanen, P., Tuuteri, L., Norio, R., Tala, P., Ahrenberg, P., and Halonen, P. (1976). Atrial myxoma in a family. American fournal of Cardiology, 38, 252-256.

Waxler, E. B., Kawai, N., and Kasparian, H. (1972). Right atrial myxoma: echocardiographic, phonocardiographic and hemodynamic signs. American Heart fournal, 83, 251-257.

Wolfe, S. B., Popp, R. L., and Feigenbaum, H. (1969). Diagnosis of atrial tumors by ultrasound. Circulation, 39, 615-622.

Yuste, P., Asin, E., Cerdan, F. J., and Fuente, A. de la (1976). Echocardiogram in right atrial myxoma. Chest, 69, 94-96.

Zajtchuk, R., Fitterer. J. D., Strevey, T. E., and Nelson, W. P. (1975). Bilateral atrial myxomas-preoperative diagnosis and successful removal. Fournal of Thoracic and Cardiovascular Surgery, 69, 291-294.

Requests for reprints to Professor J. Pernod, Hôpital Percy, 92141 Clamart, France. 